\title{
Diterpene Synthases and Their Responsible Cyclic Natural Products
}

\author{
Hai-Yan Gong $\cdot$ Ying Zeng $\cdot$ Xiao-Ya Chen
}

Received: 20 January 2014/ Accepted: 23 March 2014/Published online: 18 April 2014

(C) The Author(s) 2014. This article is published with open access at Springerlink.com

\begin{abstract}
This review provides an overview of diterpene synthases which were initially identified via genetic and/or biochemical means, traversing all organisms researched to date.

Keywords Biosynthesis $\cdot$ cDNA $\cdot$ Cyclase $\cdot$ Diterpenoid $\cdot$ Eriocalyxin B
\end{abstract}

\section{Introduction}

Naturally occurring cyclic diterpenoids are the foundation for a number of biologically important compounds, which confer anti-microbial and anti-tumor action i.e. tanshinones, Taxol, and platensimycin. They are generally derived from the linear primary metabolite $(E, E, E)$-geranylgeranyl diphosphate (GGPP) by diterpene synthases (diTPS). These enzymes undergo complex electrophilic cyclizations and/or rearrangements leading to diverse backbone structures. According to the established general patterns of diterpene biosynthesis, diTPS can be divided into two mechanistically distinct categories: class I and class II enzymes. Structural and mechanistic studies have demonstrated that class I diTPS contain a characteristic aspartate (D)-rich DDXXD

H.-Y. Gong · Y. Zeng ( $\bowtie)$

State Key Laboratory of Phytochemistry and Plant Resources in West China, Kunming Institute of Botany, Chinese Academy of Sciences, 132 Lanhei Road, Kunming 650201, China

e-mail: biochem@mail.kib.ac.cn

H.-Y. Gong

University of Chinese Academy of Sciences, Beijing 100049, China

\section{X.-Y. Chen}

National Key Laboratory of Plant Molecular Genetics, Institute of Plant Physiology and Ecology, Shanghai Institutes for Biological Sciences, Shanghai 200032, China motif that binds divalent metal ions required for the catalysis of diphosphate ionization. On the other hand, class II diTPS exhibit a typical DXDD motif which is abundant in aspartate, that confers a role in initiating cyclization by protonating the terminal $\mathrm{C}=\mathrm{C}$ double bond of GGPP $[1,2]$. Usually, the class II diTPS yield terpene diphosphates that can serve as substrates of class I diTPS. Highly reactive carbocation intermediates arise from the cleavage of diphosphate group on the substrate by class I diTPS that end the cyclization cascade, by quenching the carbocation via deprotonation or electrophilic attack by water. A significant amount of cyclic diterpenoids are known to originate biosynthetically from dual cyclization and/or rearrangement reactions, which proceed via a bicyclic diphosphate intermediate [2]. In the past decades, there has been some remarkable progress in the research of biosynthetic genes and enzymes responsible for scaffold cyclization to diterpenoids in plants, fungi, bacteria, and even animals. This review attempts to describe diTPS cloned as cDNAs and functionally characterized in all organisms researched to date, and further focusing on those first identified genetically and/or biochemically. Information regarding chemical structures of enzyme products and their relevant diterpenoid natural products will be listed in tables according to hydrocarbon backbones of the natural diterpenoids, in parallel with organisms and enzyme accession numbers released on GenBank. The same enzyme relevant to a different diterpenoid product is specifically included here. 
Table 1 Enzymes for bicyclic hydrocarbon skeletons

\begin{tabular}{lll}
\hline $\begin{array}{l}\text { Genus species (organisms), } \\
\text { enzymes/GenBank accession } \\
\text { numbers }\end{array}$ & Enzyme products & Natural diterpenoids \\
\hline
\end{tabular}

\section{Kitasatospora griseola (bacterium) $[3,4]$; terpentedienyl diphosphate synthase/BAB39206; terpentetriene synthase/ BAB39207 \\ Mycobacterium tuberculosis (bacterium) [5-7]; halimadienyl (tuberculosinyl) diphosphate synthase/CCP46198 (Rv3377c); tuberculosinol and isotuberculosinol synthase/ CCP46199 (Rv3378c)}

Selaginella moellendorffii (lycophyte) [8]; labda-7,13E-dien15-ol synthase (bifunctional)/ AEK75338

Abies balsamea (gymnosperm) [9]; cis-abienol synthase (bifunctional)/AEL99953

Nicotiana tabacum (dicot) [10]; labda-13E-8-ol diphosphate synthase/CCD33018; cis-abienol synthase/CCD33019

Cistus creticus subsp. creticus (dicot) [11]; labda-13E-8-ol diphosphate synthase/ADJ93862

Salvia sclarea (dicot) [12]; labda13E-8-ol diphosphate synthase/ AFU61897; sclareol and manool synthase/AFU61898<smiles>CC1=CCCC2[C@]1(C)CC[C@@H](C)[C@]2(C)CC/C(C)=C\CO</smiles><smiles>C=CC(=C)CC[C@]1(C)[C@H](C)CC[C@]2(C)C(C)=CCC[C@@H]21</smiles>

terpentedienyl PP terpentetriene<smiles>C/C(=C/CO)CC[C@H]1C2=CC[C@H](C)C(C)(C)[C@@H]2CCCC1(C)C</smiles>

halimadienyl PP tuberculosinol<smiles>CC1=CCC2C(C)(C)CCCC2(C)C1CC/C(C)=C/CO</smiles>

labda-7,13E-dien-15-ol<smiles>C=C[C@]1(O)CCC2C(C)(C)CCC[C@]2(C)[C@H]1CC=C(C)CO</smiles><smiles>C=C1C(C)=CC[C@@H]2C(C[PH2+])[C@@]3(C)CCCC(C)(C)C3CC[C@]12O</smiles>

labda-13E-8-ol PP cis-abienol labda-13E-8-ol PP

labda-13E-8-ol PP sclareol

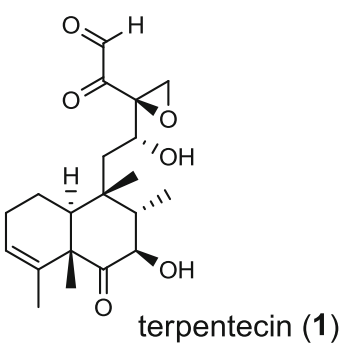<smiles>C=CC(C)(O)C[C@@H]1C2CCCC(C)(C)C2=CC[C@@H]1C</smiles>

$13 R, S$-isotuberculosinol (2, nosyberkol)<smiles>CC1=CCC2C(C)(C)CCCC2(C)C1CC/C(C)=C/CO</smiles>

labda-7,13E-dien-15-ol (3)<smiles>C=C1C(C)=CC[C@H]2[C@@]3(C)CCCC(C)(C)C3CC[C@]12O</smiles><smiles>C=C1C(C)=CC[C@H]2[C@@H]1CCC1C(C)(C)CCC[C@]12O</smiles><smiles>C=C[C@]1(C)CC[C@@H]2[C@H](CCC3C(C)(C)CCC[C@]32C)O1</smiles>
labdenediol (5) manoyl oxide (6)<smiles>C=C[C@]1(C)CC[C@@H]2[C@](C)(CCC3C(C)(C)CCC[C@]32C)O1</smiles>

manoyl oxide (6)<smiles>C=C[C@]1(O)CC[C@@H]2C(C)(C)CCC[C@]2(C)[C@@H]1O</smiles>

sclareol (7)<smiles>C=C1CC[C@H]2C3(CC3(C)CCC[C@@]2(C)O)[C@@H]1C</smiles>

manool (8)

\section{Enzymes for Bicyclic Hydrocarbon Skeletons (Table 1)}

The first diTPS of prokaryotic origin was reported in Streptomyces griseolosporeus MF730-N6 (currently referred to as Kitasatospora griseola), a diterpenoid antibiotic terpentecin (1) producer. Using the general diterpenoid precursor GGPP as its substrate, the class II terpentedienyl diphosphate synthase produces a bicyclic terpentedienyl diphosphate (PP) which is then transformed 
to terpentetriene by the class I terpentetriene synthase. These two enzymes are involved in terpentecin (1) biosynthesis [3, 4]. In Mycobacterium tuberculosis H37, a bacterium causing fatal infections of tuberculosis, via the bicyclization of GGPP by the class II Rv3377c, produces halimadienyl (tuberculosinyl) PP that undergoes subsequent ionization-dependent re-arrangement catalyzed by the class I Rv3378c to give tuberculosinol \{5(6),13-halimadiene-15-ol $\}$ and isotuberculosinol (2, also known as nosyberkol) [5-7]. Interestingly, the two diTPS genes are specifically found in the virulent species, but not in the avirulent species [7].

The basal vascular land plant lycophyte Selaginella moellendorffii contains a class I/II bi-functional enzyme labda-7,13E-dien-15-ol synthase that directly generates the endocyclic double bond and the hydroxyl group to form the bicyclic product labda-7,13E-dien-15-ol (3) [8]. The labdanoid diterpene alcohol cis-abienol (4) is a major component of the aromatic oleoresin of the gymnosperm balsam fir (Abies balsamea) and serves as a valuable bioproduct material for the fragrance industry. A bi-functional class I/II cis-abienol synthase (AbCAS) was discovered using high-throughput 454 transcriptome sequencing and metabolite profiling of balsam fir bark tissue [9]. AbCAScatalyzed formation of $c i s$-abienol (4) proceeds via cyclization and hydroxylation at carbon $\mathrm{C}-8$ of a postulated carbocation intermediate in the class II active site, followed by cleavage of the diphosphate group and termination of the reaction sequence without further cyclization in the class I active site [9]. In the leaves of the angiosperm tobacco (Nicotiana tabacum) there are two consecutive reactions catalyzed by separate diTPS which lead to the production of $c i s$-abienol (4). Accordingly, a labda-13E-8ol PP synthase (NtCPS2) encodes a class II diterpene synthase that produces labda-13E-8-ol PP from GGPP; NtABS encodes a class I diterpene synthase that uses labda-13E-8-ol PP to form cis-abienol (4) [10].

Another labda-13E-8-ol PP synthase from Cistus creticus subsp. creticus was found to catalyze cyclization of GGPP to labda-13E-8-ol (copal-8-ol) PP, a likely intermediate in the biosynthesis of the oxygen-containing labdane-type diterpenes labdenediol (5) and manoyl oxide (6) abundant in the resin of this plant [11]. The bicyclic sclareol (7) extracted from cultivated clary sage (Salvia sclarea) is a diterpene natural product of high value for the fragrance industry and a valued starting material for semisynthesis of numerous commercial substances, including production of Ambrox ${ }^{\circledR}$. Similar to the labdanoid alcohols in two dicot plants mentioned above, sclareol (7) and manool $(\mathbf{8})$ were produced in a two-step process mediated sequentially by labda-13E-8-ol PP synthase and sclareol/ manool synthase [12]. Only a few diTPS generate the hydroxylated diterpenoids without requirement for additional oxidation by enzymes like cytochrome P450 monooxygenases.

\section{Enzymes for Tricyclic Hydrocarbon Skeletons (Table 2)}

The ent-copalyl diphosphate (CPP) synthase and pimara9(11),15-diene synthase from Streptomyces sp. strain KO3988, is responsible for ent-CPP and pimara-9(11),15diene formation, respectively, and were confirmed to participate in viguiepinol (9) \{3-hydroxypimara-9(11),15diene biosynthesis by a heterologous expression experiment [13, 14]. Notably, Rv3378c from Mycobacterium tuberculosis $\mathrm{H} 37$ was found to encode an unusual halimadienyl PP specific class I diterpene synthase that is primarily involved in the production of the tricyclic edaxadiene (10) [15]. Platensimycin (PTM, 11) and platencin (PTN, 12) harbor diterpene moieties were isolated from Streptomyces platensis strains. They exhibit inhibitory activity toward bacterial and mammalian fatty acid synthases and have great potential in anti-bacterial and anti-diabetic drug development $[16,17]$. Their biosyntheses are controlled by dedicated ent-kaurene synthase (PtmT3) and ent-atiserene synthases (PtmT1 and PtnT1) that channel the common ent-CPP precursor formed by the ent-CPP synthases (PtmT2 and PtnT2) to the characteristic PTM and PTN scaffolds, respectively. Therefore, the class I diterpene synthases PtmT1 and PtnT1 represent the first ent-atiserene synthases discovered, unveiling a previously undescribed pathway for the biosynthesis of diterpenoid natural products from the common precursor ent-CPP [16, 17]. The lysophospholipase inhibitor cyclooctatin (13) from Streptomyces melanosporofaciens MI614-43F2 is characterized by a 5-8-5 fused ring system. Sequence analysis in combination with sub-cloning and gene deletion revealed that the CotB2 gene encodes an enzyme that acts as a class I diTPS to produce cyclooctat-9-en-7-ol from GGPP [18]. The reaction is most likely to be initiated by ionization of the diphosphate of GGPP and followed by proton-induced cyclization, employing a similar mechanism underlying the taxadiene formation in taxol biosynthesis [18]. Harboring the same 5-8-5 fused ring scaffold, fusicoccins (14) are the major metabolites produced by the plant-pathogenic fungus Phomopsis (originally known as Fusicoccum) amygdali (Del.). They function as potent activators of plasma membrane $\mathrm{H}^{+}$-ATPase in plants and also exhibit unique biological activity in animal cells. The tricyclic hydrocarbon skeleton of fusicoccin A (14) is biosynthesized by an unusual multifunctional enzyme, $P$. amygdali fusicoccadiene synthase (PaFS) showing both prenyltransferase and terpene synthase activities [19]. Equipped with a terpene synthase domain at the $\mathrm{N}$ terminus 


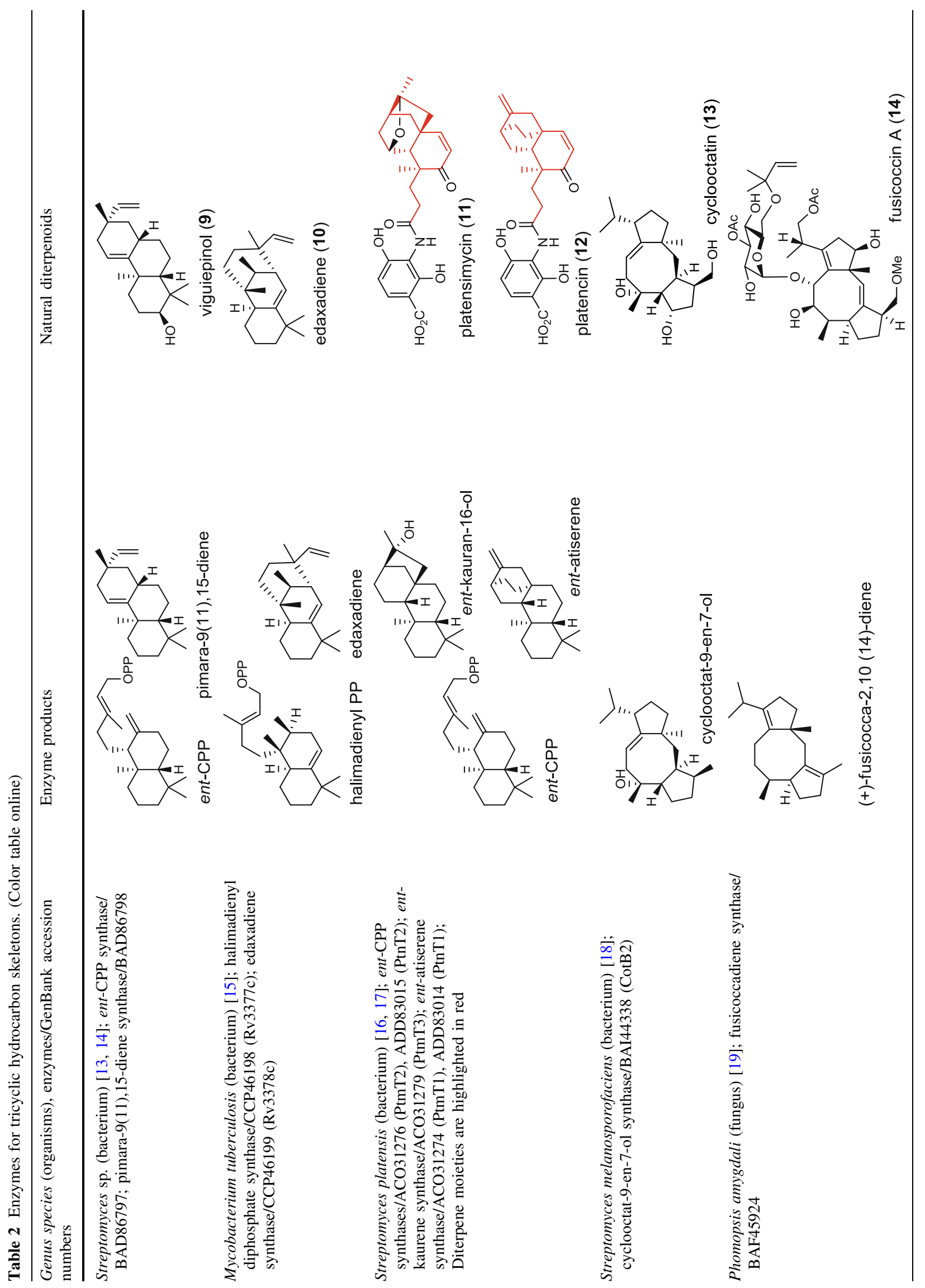




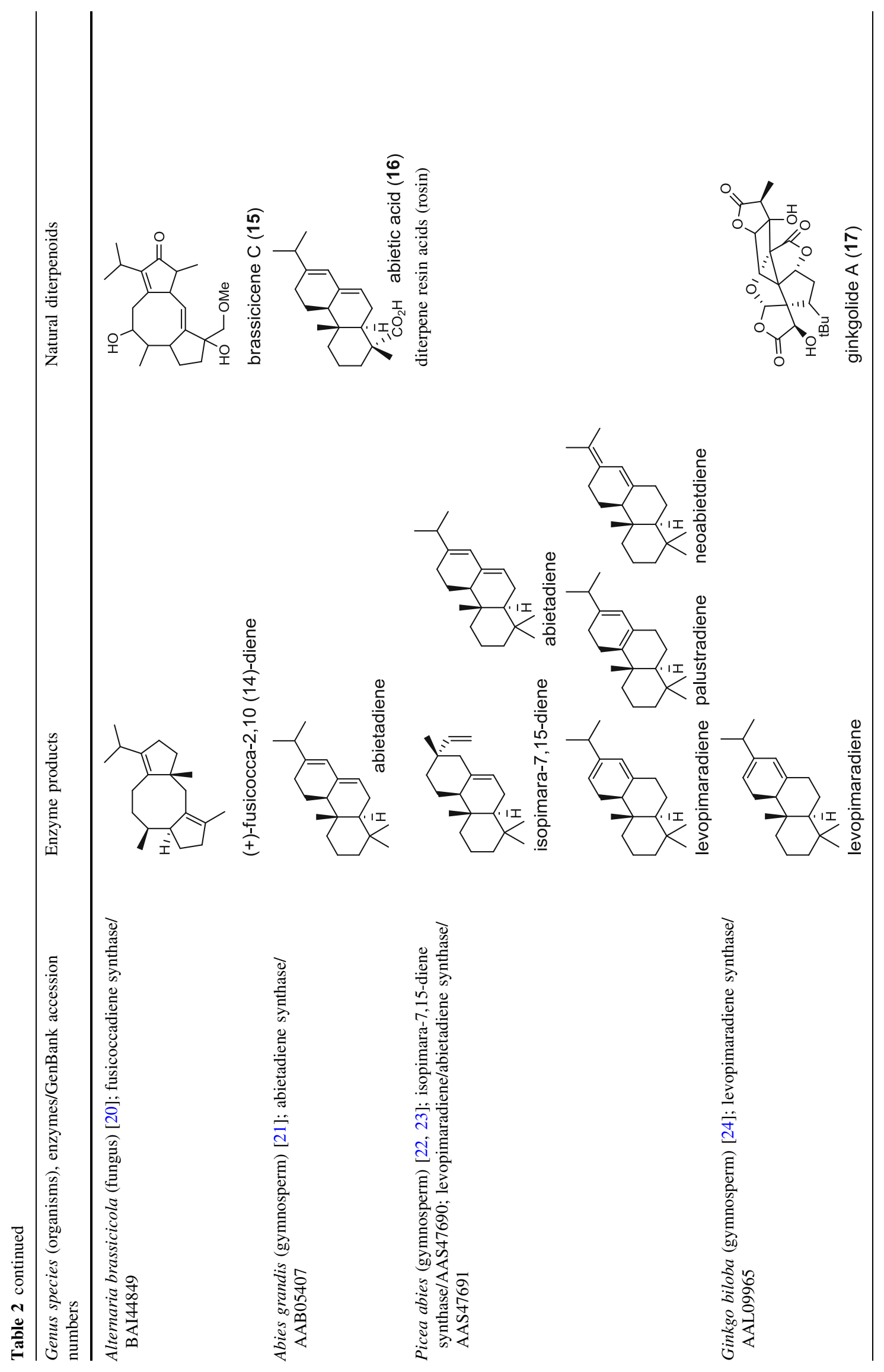




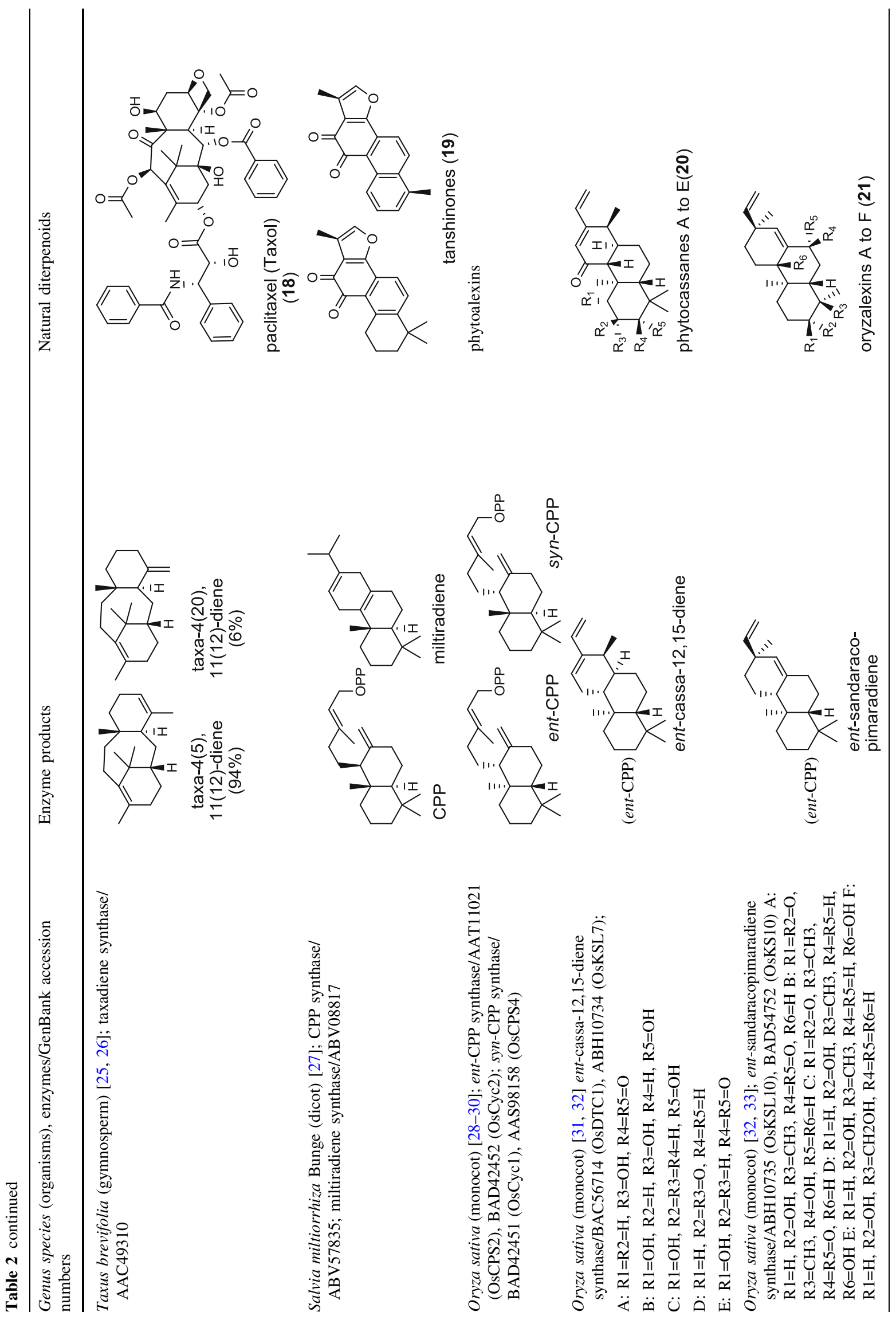




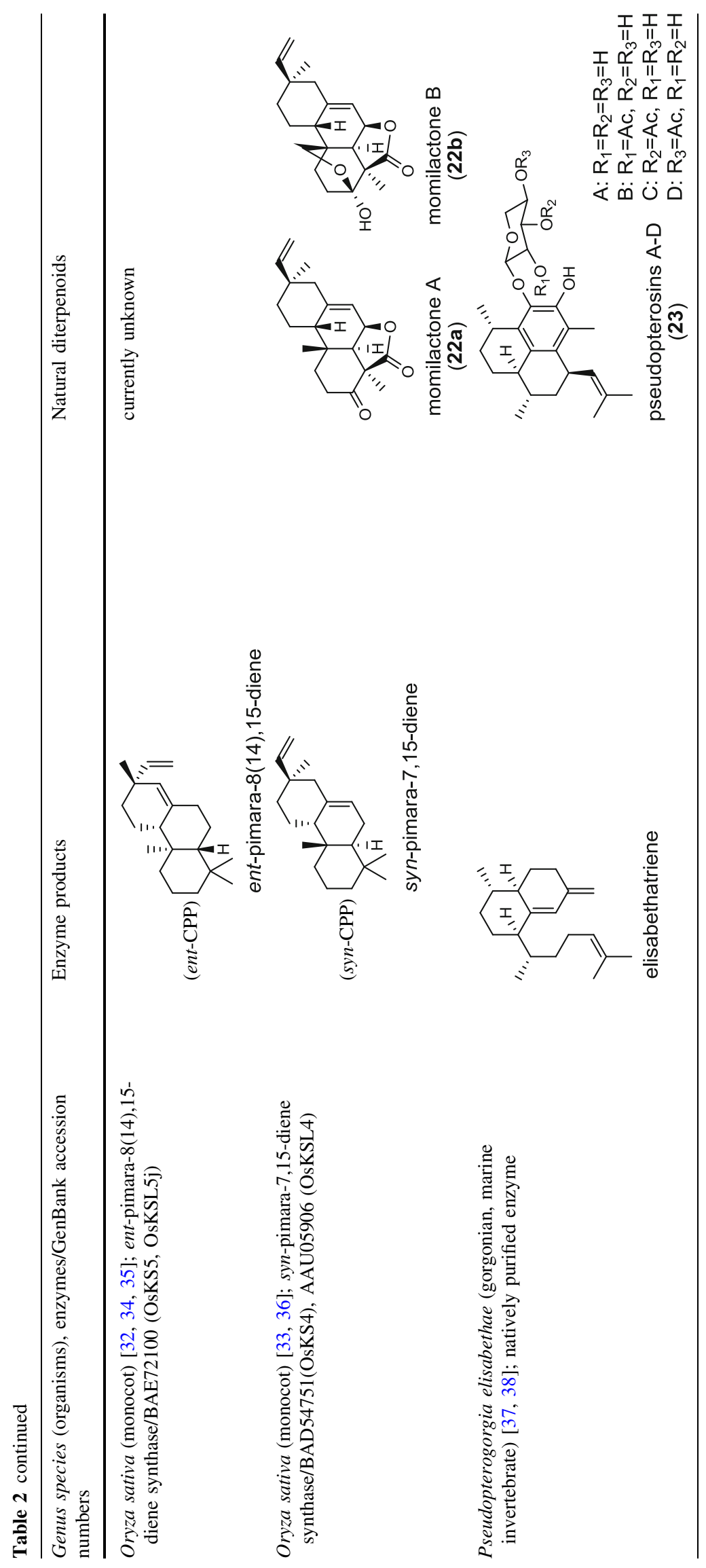


and a GGPP synthase domain at the $\mathrm{C}$ terminus, PaFS is able to form GGPP and the resulting (+)-fusicocca2,10(14)-diene using $C_{5}$ isoprene units as precursors [19]. Another fusicoccadiene synthase was identified in the fungus Alternaria brassicicola strain ATCC 96836 for the brassicicene $\mathrm{C}(\mathbf{1 5})$ biosynthesis in a similar manner to that of PaFS [20].

Diterpene resin acids (16, rosin) secreted by the gymnosperm conifer species are important defense compounds against herbivores and pathogens. The abietadiene synthase from grand fir (Abies grandis; AgAS) is the first diterpene synthase in conifers to be cloned and functionally characterized, and also a bifunctional diTPS catalyzing both protonation-initiated and ionization-initiated cyclization steps for rosin biosynthesis [21]. The AgAS's homologues from Norway spruce (Picea abies), isopimara-7,15-diene synthase and levopimaradiene/abietadiene synthase (PaLAS), produce isopimara-7,15-diene and a mixture of levopimaradiene, abietadiene, neoabietadiene, and palustradiene, respectively, when incubating with GGPP as substrate [22]. The initial product of PaLAS, however, may be epimers of the thermally unstable allylic tertiary alcohol 13-hydroxy-8(14)-abietene that is likely by dehydration to yield a mixture of the above four diterpene hydrocarbons [23]. Another homologue from Ginkgo biloba encodes a bifunctional levopimaradiene synthase catalyzing the initial cyclization step in ginkgolide (17) pathway [24]. Biosynthesis of the anticancer drug Taxol (18) in Taxus (yew) species involves 19 steps from GGPP that first cyclizes to the taxane skeleton by taxadiene synthase [25, 26].

Tanshinones (19) are abietane-type norditerpenoid quinone natural products in the Chinese medicinal herb Dānshēn (Salvia miltiorrhiza Bunge). The CPP synthase and miltiradiene synthase cDNAs have been cloned from the induced root tissue and demonstrated to be involved in the biosynthesis of tanshinones [27]. In the monocot plant rice (Oryza sativa, O. glaberrima), the diterpenoid phytoalexins have been identified to derive via the common biosynthetic origins in the initiating dual cyclization and/or rearrangement of GGPP precursor. The ent-CPP synthase (OsCPS2/ OsCyc2) paired with ent-cassa-12,15-diene and ent-sandaracopimaradiene synthases, respectively, give rise to phytocassanes A-E (20) and oryzalexins A-F (21) [28-33]. An ent-CPP specific ent-pimara-8(14),15-diene synthase was discovered in spite of its currently unknown products [32, 34, 35]. In addition, the dual phytoalexin/allelochemical momilactones (22a and 22b) are formed by tandem catalysis of syn-CPP synthase (OsCPS4/OsCyc1) and syn-pimara7,15 -diene synthase $[33,36]$. The only animal diTPS which has been reported is a natively purified enzyme from a marine invertebrate gorgonian (Pseudopterogorgia elisabethae), which shows elisabethatriene synthase activity presumably linked to the formation of pseudopterosins $(\mathbf{2 3})[37,38]$.

\section{Enzymes for Tetracyclic Hydrocarbon Skeletons (Table 3)}

The ubiquitous gibberellin phytohormones (24a-c) are tetracyclic diterpenoids produced via distinct biosynthetic pathways by plants, fungi, and bacteria. Like in plants, the bacterium Bradyrhizobium japonicum was demonstrated to encodes for separate ent-CPP and ent-kaurene synthases for gibberellic acid $\mathrm{GA}_{3}$ production (24a) [39]; while fungi use only a single bi-functional ent-kaurene synthase for $\mathrm{GA}_{1}$ (24b) [40]. Aphidicolin (25) isolated from the fungus Phoma betae PS-13 has a unique hydrocarbon skeleton and remarkable bio-activity such as anti-tumor and specific inhibition of DNA polymerase $\alpha$. Aphidicolan-16 $\beta$-ol synthase was identified as a bifunctional diTPS involved in the biosynthesis of aphidicolin (25) from GGPP via synCPP [41]. However, the metabolite phyllocladan$11 \alpha, 16 \alpha, 18$-triol (26) is likely to result from a two-step cyclization via CPP synthase coupled with phyllocladan$16 \alpha$-ol synthase in the fusicoccin (14)-producing fungus Phomopsis amygdali [19, 42]. Using homology based PCR of GGPP synthase genes and the subsequent genome walking in the fungus Phomopsis amygdali N2, phomopsene synthase was identified and led to discovery of a new diterpene, methyl phomopsenonate (27) [43].

In the basal vascular land plant moss Physcomitrella patens, a bifunctional ent-CPS/KS directly generates the ent-kaurene skeleton from GGPP to give ent-kaurene (28), 16 $\alpha$-hydroxy-ent-kaurane (29) and ent-kaurenoic acid (30) [44-46]. Instead, most angiosperms use normal, ent, or synCPP synthase and kaurene synthase or kaurene synthaselike (KSL) for the two sequential cyclization reactions that initiate biosyntheses of gibberellins such as $\mathrm{GA}_{4}(\mathbf{2 4 c})$ and labdane-related diterpenoids. The plant gibberellin diTPS were the first identified in Arabidopsis thaliana and $\mathrm{Cu}$ curbita maxima, respectively [47, 48]. Interestingly, the intensely sweet steviol (31) producing plant Stevia rebaudiana was found to share the same ent-CPP synthase and ent-kaurene synthase for both gibberellin and steviol (31) biosyntheses [49]. In contrast, Isodon plants are most likely to recruit novel a diTPS that functions as an ent-CPP synthase specific for the production of ent-kaurane diterpenoids (also ent-kauranoids) like eriocalyxin B (32) [50]. The induced accumulation of six ent-kaurane-related diterpenoid phytoalexins, collectively termed kauralexins (33) was observed in maize in response to stem attack by the European corn borer (Ostrinia nubilalis) and fungi. The maize An2 encoding an ent-CPP synthase, is probably relevant to kauralexin (33) production $[51,52]$. Besides tricyclic diterpenoid phytoalexins as described in Table 2, rice produces tetracyclic phytoalexins such as oryzalides (34) and oryzalexin S (35). The ent-CPP synthase (OsCPS2/OsCyc2) and ent-isokaurene synthase in tandem 


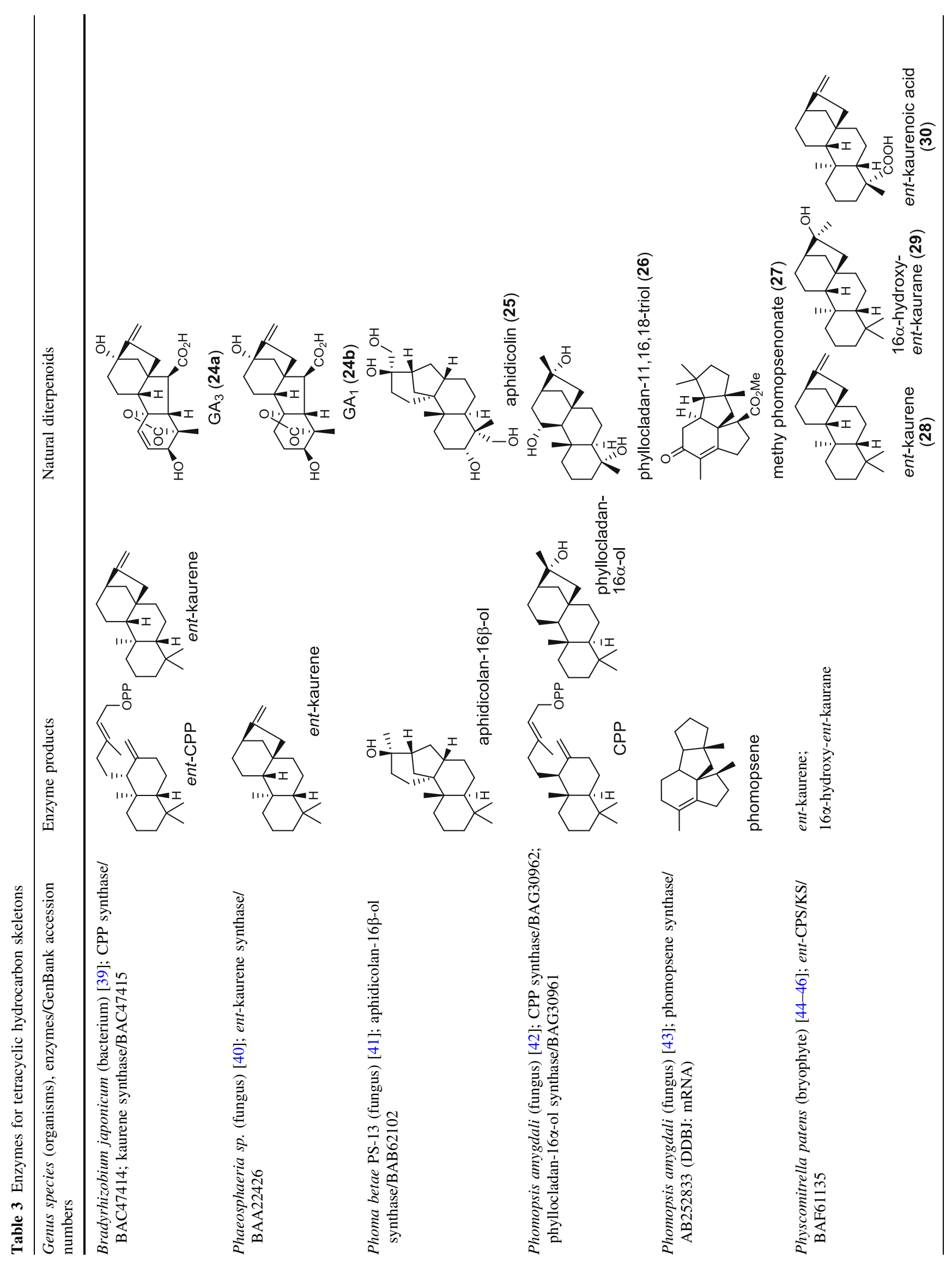




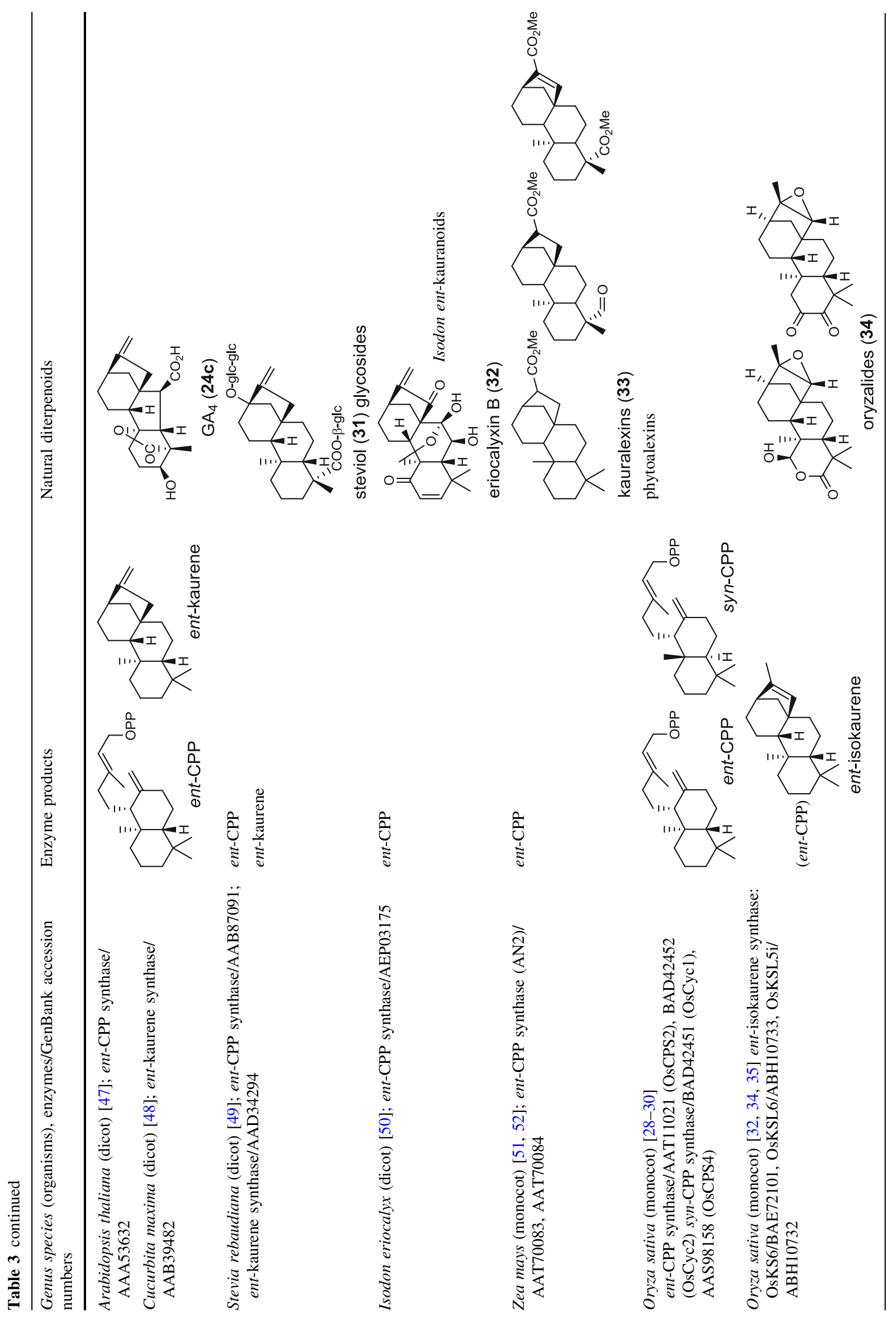




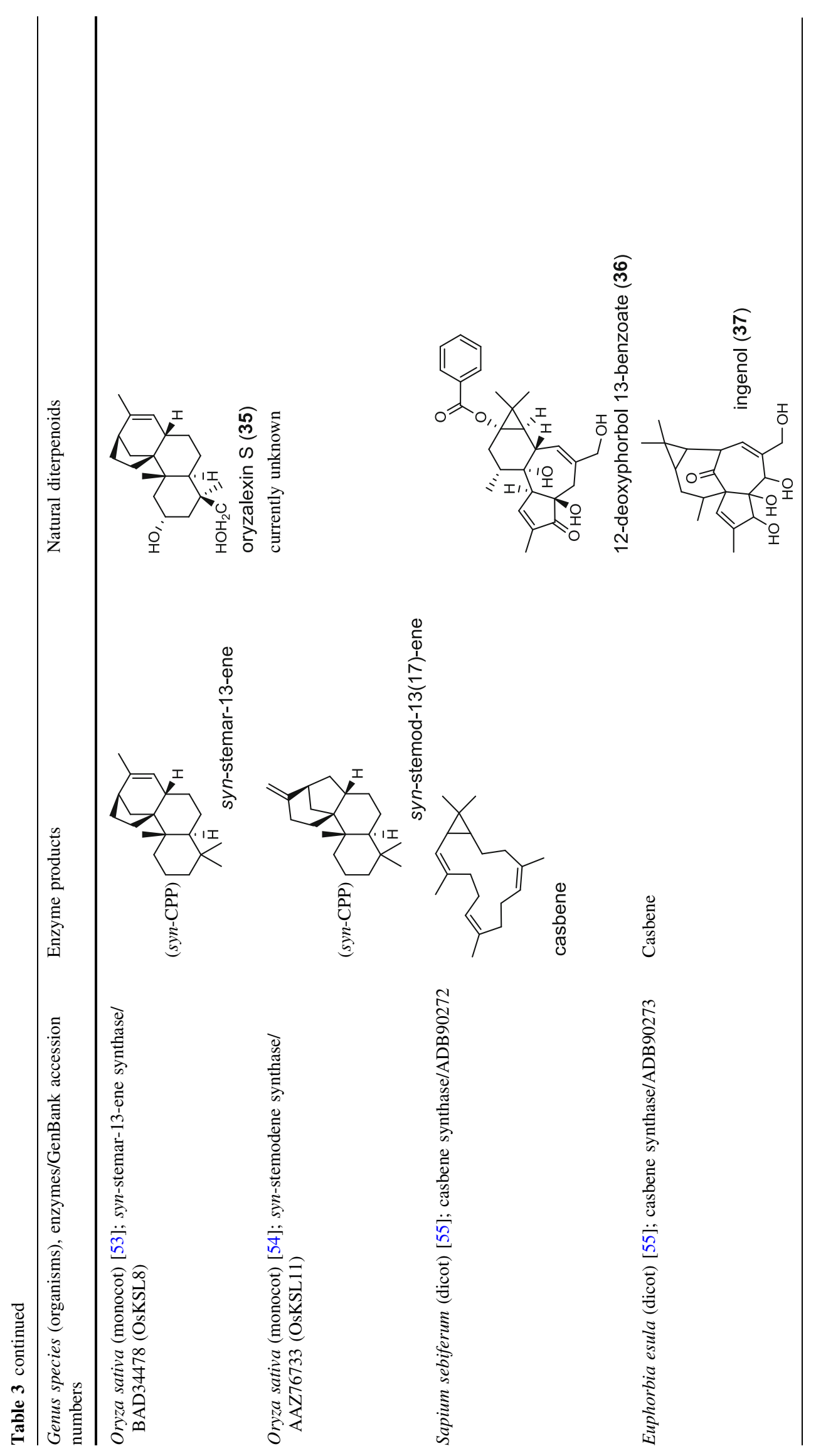


catalyze the formation of hydrocarbon skeletons of oryzalides (34) [32; 34, 35]; wherase the syn-CPP synthase (OsCPS4/OsCyc1) coupled with syn-stemar-13-ene synthase generate those of oryzalexin S (35) [53]. Despite the demonstration of syn-CPP specific syn-stemodene synthase activity in rice, its relevant natural product has remained elusive [54]. The latent HIV-1 activator prostratin (and related 12-deoxyphorbol esters), the analgesic resiniferatoxin, and the anti-cancer drug candidate ingenol 3-angelate are Euphorbiaceae diterpenoids of medical interest and likely derived from casbene. Casbene synthase genes were considered for carbon skeletons formation of 12-deoxyphorbol 13-benzoate (36) and ingenol (37), respectively in Sapium sebiferum and Euphorbia esula [55].

\section{Enzymes for Macrocyclic Hydrocarbon Skeletons} (Table 4)

Two novel class I diTPS DtcycA and DtcycB, derived from Streptomyces sp. SANK 60404, are capable of forming multiple diterpene products with macrocyclic skeletons. The reaction products catalyzed by DtcycA were determined to be the isopropylidene isomer of cembrene $\mathrm{C}$ (38) and $(R)$-nephthenol (39); while the outcome of DtcycB included $(R)$-nephthenol (39), $(R)$-cembrene $\mathrm{A}(\mathbf{4 0})$, and a novel diterpene $\{(4 E, 8 E, 12 E)-2,2,5,9,13$-pentamethylcyclopentadeca-4,8,12-trien-1-ol\} (41) [56]. However, none of these diterpene products were detected in the culture broths under any of the culture conditions used in this study, as revealed by GC-MS analysis. Furthermore, DtcycA and DtcycB show no sequence similarity to cembratrieneol synthase for cembratrienediol (42) in Nicotiana tabacum [57] or to neocembrene (43) (also known as cembrene A) synthase (CAS2) from castor bean (Ricinus communis) [55]. Casbene (44) is a macrocyclic diterpene hydrocarbon that serves as a phytoalexin in castor bean [58]. The casbene synthase from castor bean is the first diTPS cloned as cDNA as early as in 1994 [59].

In summary, angiosperm plants and bacteria generally share the common two-step process that shapes the hydrocarbon cyclic skeletons of diterpenoids by two monofunctional diTPS in tandem catalysis. Such a correlation seems plausible considering that the plastidial MEP (2-Cmethyl-D-erythritol phosphate) pathway dominates the $\mathrm{C}_{5}$ isoprene precursor supplies and plastids are thought to have

Table 4 Enzymes for macrocyclic hydrocarbon skeletons

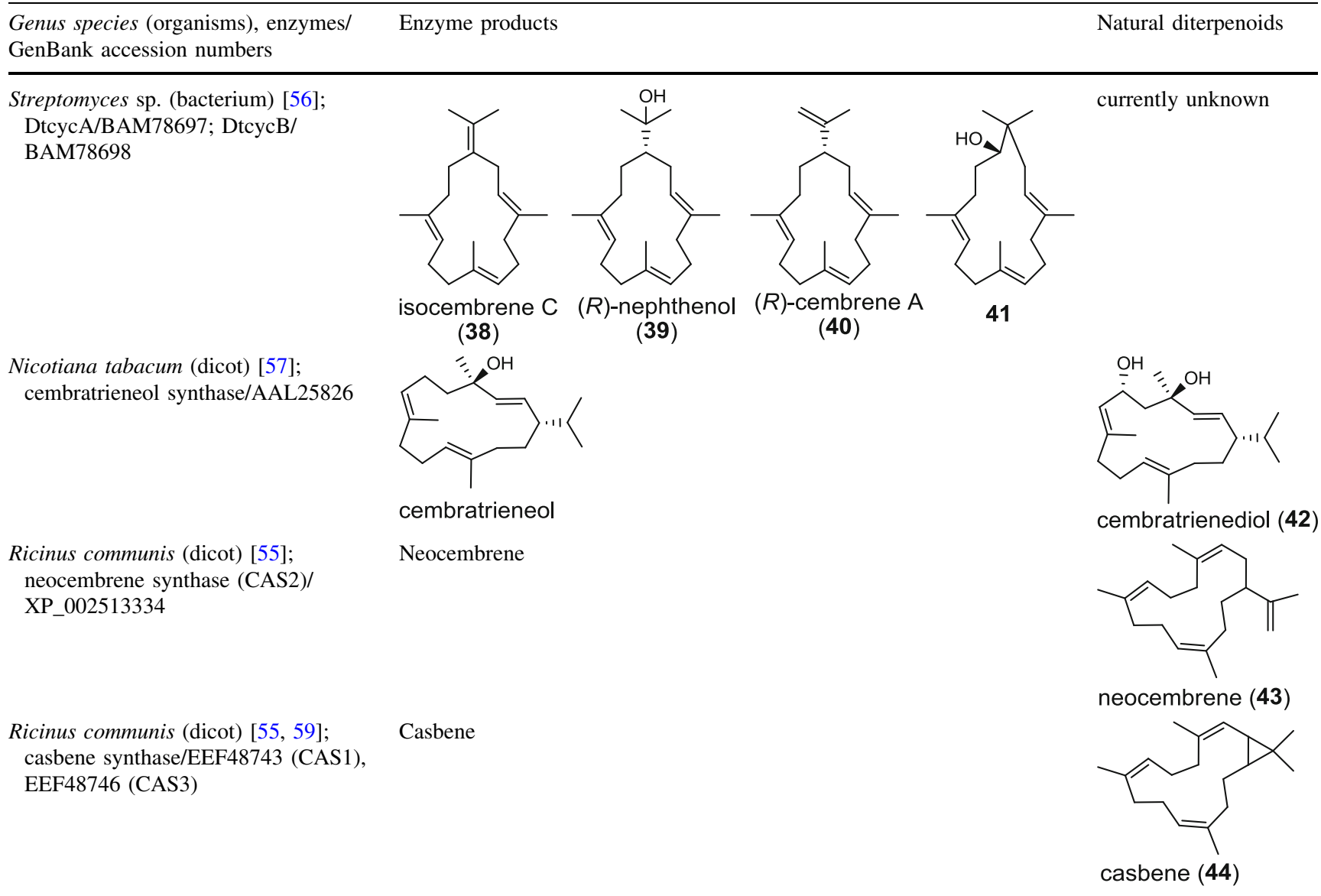


originated from endosymbiotic cyanobacteria. Conversely, bi-functional class I/II diTPS are more likely found in gymnosperms, basal vascular land plants, and fungi. Currently, only class I diTPS can produce macrocyclic skeletons of natural diterpenoids. In the near future, 'Omics' approaches and metabolite profiling can be extensively exploited in an effort to reveal genes and enzymes responsible for cyclization and subsequent modification reactions that take place in diterpenoid biosyntheses of plants, fungi, and bacteria.

Acknowledgments This study was supported by grants from the National Key Laboratory of Plant Molecular Genetics, and from the State Key Laboratory of Phytochemistry and Plant Resources in West China.

Conflicts of interest The authors declare no conflict of interest.

Open Access This article is distributed under the terms of the Creative Commons Attribution License which permits any use, distribution, and reproduction in any medium, provided the original author(s) and the source are credited.

\section{References}

1. D.W. Christianson, Chem. Rev. 106, 3412-3442 (2006)

2. R.J. Peters, Nat. Prod. Rep. 27, 1521-1530 (2010)

3. T. Dairi, Y. Hamano, T. Kuzuyama, N. Itoh, K. Furihata, H. Seto, J. Bacteriol. 183, 6085-6094 (2001)

4. Y. Hamano, T. Kuzuyama, N. Itoh, K. Furihata, H. Seto, T. Dairi, J. Biol. Chem. 277, 37098-37104 (2002)

5. C. Nakano, T. Okamura, T. Sato, T. Dairi, T. Hoshino, Chem. Commun. 8, 1016-1018 (2005)

6. C. Nakano, T. Hoshino, ChemBioChem 10, 2060-2071 (2009)

7. C. Nakano, T. Ootsuka, K. Takayama, T. Mitsui, T. Sato, T. Hoshino, Biosci. Biotechnol. Biochem. 75, 75-81 (2011)

8. S. Mafu, M.L. Hillwig, R.J. Peters, ChemBioChem 12, 1984-1987 (2011)

9. P. Zerbe, A. Chiang, M. Yuen, B. Hamberger, B. Hamberger, J.A. Draper, R. Britton, J. Bohlmann, J. Biol. Chem. 287, 12121-12131 (2012)

10. C. Sallaud, C. Giacalone, R. Töpfer, S. Goepfert, N. Bakaher, S. Rösti, A. Tissier, Plant J. 72, 1-17 (2012)

11. V. Falara, E. Pichersky, A.K. Kanellis, Plant Physiol. 154, 301-310 (2010)

12. A. Caniard, P. Zerbe, S. Legran, A. Cohade, N. Valot, J.L. Magnard, J. Bohlmann, L. Legendre, BMC Plant Biol. 12, 119 (2012)

13. T. Kawasaki, T. Kuzuyama, Y. Kuwamori, N. Matsuura, N. Itoh, K. Furihata, H. Seto, T. Dairi, J. Antibiot. 57, 739-747 (2004)

14. C. Ikeda, Y. Hayashi, N. Itoh, H. Seto, T. Dairi, J. Biochem. 141, 37-45 (2007)

15. F.M. Mann, M. Xu, X. Chen, D.B. Fulton, D.G. Russell, R.J. Peters, J. Am. Chem. Soc. 131, 17526-17527 (2009)

16. M.J. Smanski, Z. Yu, J. Casper, S. Lin, R.M. Peterson, Y. Chen, E. Wendt-Pienkowski, S.R. Rajski, B. Shen, Proc. Natl. Acad. Sci. U.S.A. 108, 13498-13503 (2011)

17. M.J. Smanski, R.M. Peterson, S.-X. Huang, B. Shen, Curr. Opin. Chem. Biol. 16, 132-141 (2012)
18. S.Y. Kim, P. Zhao, M. Igarashi, R. Sawa, T. Tomita, M. Nishiyama, T. Kuzuyama, Chem. Biol. 16, 736-743 (2009)

19. T. Toyomasu, M. Tsukahara, A. Kaneko, R. Niida, W. Mitsuhashi, T. Dairi, N. Kato, T. Sassa, Proc. Natl. Acad. Sci. U.S.A. 104, 3084-3088 (2007)

20. A. Minami, N. Tajima, Y. Higuchi, T. Toyomasu, T. Sassa, N. Kato, T. Dairi, Bioorg. Med. Chem. Lett. 19, 870-874 (2009)

21. B.S. Vogel, M.R. Wildung, G. Vogel, R. Croteau, J. Biol. Chem. 271, 23262-23268 (1996)

22. D.M. Martin, J. Fäldt, Bohlmann, J. Plant Physiol. 135, 1908-1927 (2004)

23. C.I. Keeling, L.L. Madilao, P. Zerbe, H.K. Dullat, J. Bohlmann, J. Biol. Chem. 286, 21145-21153 (2011)

24. H.G. Schepmann, J. Pang, S.P. Matsuda, Arch. Biochem. Biophys. 392, 263-269 (2001)

25. M.R. Wildung, R. Croteau, J. Biol. Chem. 271, 9201-9204 (1996)

26. R. Croteau, R.E.B. Ketchum, R.M. Long, R. Kaspera, M.R. Wildung, Phytochem. Rev. 5, 75-97 (2006)

27. W. Gao, M.L. Hillwig, L. Huang, G. Cui, X. Wang, J. Kong, B. Yang, R.J. Peters, Org. Lett. 11, 5170-5173 (2009)

28. S. Prisic, M. Xu, P.R. Wilderman, R. Peters, J. Plant Physiol. 136, 4228-4236 (2004)

29. K. Otomo, H. Kenmoku, H. Oikawa, W.A. König, H. Toshima, W. Mitsuhashi, H. Yamane, T. Sassa, T. Toyomasu, Plant J. 39, 886-893 (2004)

30. M. Xu, M.L. Hillwig, S. Prisic, R.M. Coates, R.J. Peters, Plant J. 39, 309-318 (2004)

31. E.M. Cho, A. Okada, H. Kenmoku, K. Otomo, T. Toyomasu, W. Mitsuhashi, T. Sassa, A. Yajima, G. Yabuta, K. Mori, H. Oikawa, H. Toshima, N. Shibuya, H. Nojiri, T. Omori, M. Nishiyama, H. Yamane, Plant J. 37, 1-8 (2004)

32. M. Xu, P.R. Wilderman, D. Morrone, J. Xu, A. Roy, M. MargisPinheiro, N.M. Upadhyaya, R.M. Coates, R.J. Peters, Phytochemistry 68, 312-326 (2007)

33. K. Otomo, Y. Kanno, A. Motegi, H. Kenmoku, H. Yamane, W. Mitsuhashi, H. Oikawa, H. Toshima, H. Itoh, M. Matsuoka, T. Sassa, T. Toyomasu, Biosci. Biotechnol. Biochem. 68, 2001-2006 (2004)

34. Y. Kanno, K. Otomo, H. Kenmoku, W. Mitsuhashi, H. Yamane, H. Oikawa, H. Toshima, M. Matsuoka, T. Sassa, T. Toyomasu, Biosci. Biotechnol. Biochem. 70, 1702-1710 (2006)

35. M. Xu, P.R. Wilderman, R.J. Peters, Proc. Natl. Acad. Sci. U.S.A. 104, 7397-7401 (2007)

36. P.R. Wilderman, M. Xu, Y. Jin, R.M. Coates, R. Peters, J. Plant Physiol. 135, 2098-2105 (2004)

37. A.C. Kohl, R.G. Kerr, Arch. Biochem. Biophys. 424, 97-104 (2004)

38. T.B. Brück, R.G. Kerr, Comp. Biochem. Physiol. B-Biochem. Mol. Biol. 143, 269-278 (2006)

39. D. Morrone, J. Chambers, L. Lowry, G. Kimc, A. Anterola, K. Bender, R.J. Peters, FEBS Lett. 583, 475-480 (2009)

40. H. Kawaide, R. Imai, T. Sassa, Y. Kamiya, J. Biol. Chem. 272, 21706-21712 (1997)

41. H. Oikawa, T. Toyomasu, H. Toshima, S. Ohashi, H. Kawaide, Y. Kamiya, M. Ohtsuka, S. Shinoda, W. Mitsuhashi, T. Sassa, J. Am. Chem. Soc. 123, 5154-5155 (2001)

42. T. Toyomasu, R. Niida, H. Kenmoku, Y. Kanno, S. Miura, C. Nakano, Y. Shiono, W. Mitsuhashi, H. Toshima, H. Oikawa, T. Hoshino, T. Dairi, N. Kato, T. Sassa, Biosci. Biotechnol. Biochem. 72, 1038-1047 (2008)

43. T. Toyomasu, A. Kaneko, T. Tokiwano, Y. Kanno, Y. Kanno, R. Niida, S. Miura, T. Nishioka, C. Ikeda, W. Mitsuhashi, T. Dairi, T. Kawano, H. Oikawa, N. Kato, T. Sassa, J. Org. Chem. 74, 1541-1548 (2009) 
44. K. Hayashi, H. Kawaide, M. Notomi, Y. Sakigi, A. Matsuo, H. Nozaki, FEBS Lett. 580, 6175-6181 (2006)

45. K. Hayashi, K. Horie, Y. Hiwatashi, H. Kawaide, S. Yamaguchi, A. Hanada, T. Nakashima, M. Nakajima, L.N. Mander, H. Yamane, M. Hasebe, H. Nozaki, Plant Physiol. 153, 1085-1097 (2010)

46. H. Kawaide, K. Hayashi, R. Kawanabe, Y. Sakigi, A. Matsuo, M. Natsume, H. Nozaki, FEBS J. 278, 123-133 (2011)

47. T.P. Sun, Y. Kamiya, Plant Cell 6, 1509-1518 (1994)

48. S. Yamaguchi, T. Saito, H. Abe, H. Yamane, N. Murofushi, Y. Kamiya, Plant J. 10, 203-213 (1996)

49. A.S. Richman, M. Gijzen, A.N. Starratt, Z.Y. Yang, J.E. Brandle, Plant J. 19, 411-421 (1999)

50. J.L. Li, Q.Q. Chen, Q.P. Jin, J. Gao, P.J. Zhao, S. Lu, Y. Zeng, Phytochemistry 76, 32-39 (2012)

51. L.J. Harris, A. Saparno, A. Johnston, S. Prisic, M. Xu, S. Allard, A. Kathiresan, T. Ouellet, R.J. Peters, Plant Mol. Biol. 59, 881-894 (2005)
52. E.A. Schmelz, F. Kaplan, A. Huffaker, N.J. Dafoe, M.M. Vaughan, X. Ni, J.R. Rocca, H.T. Alborn, P.E. Teal, Proc. Natl. Acad. Sci. U.S.A. 108, 5455-5460 (2011)

53. T. Nemoto, E.M. Cho, A. Okada, K. Okada, K. Otomo, Y. Kanno, T. Toyomasu, W. Mitsuhashi, T. Sassa, E. Minami, N. Shibuya, M. Nishiyama, H. Nojiri, H. Yamane, FEBS Lett. 571, 182-186 (2004)

54. D. Morrone, Y. Jin, M. Xu, S.Y. Choi, R.M. Coates, R.J. Peters, Arch. Biochem. Biophys. 448, 133-140 (2006)

55. J. Kirby, M. Nishimoto, J.G. Park, S.T. Withers, F. Nowroozi, D. Behrendt, E.J.G. Rutledge, J.L. Fortman, H.E. Johnson, J.V. Anderson, J.D. Keasling, Phytochemistry 71, 1466-1473 (2010)

56. A. Meguro, T. Tomita, M. Nishiyama, T. Kuzuyama, ChemBioChem 14, 316-321 (2013)

57. E. Wang, G.J. Wagner, Planta 216, 686-691 (2003)

58. D. Sitton, C. West, A. Phytochemistry 14, 1921-1925 (1975)

59. C.J. Mau, C.A. West, Proc. Natl. Acad. Sci. U.S.A. 91, 8497-8501 (1994) 